\title{
0 paradoxo do conceito de representação política
}

\author{
The paradox of the concept of political representation
}

\author{
Antonio Carlos Alkmim \\ Doutor em Ciência Política pelo IUPERJ, Pesquisador \\ sênior do IBGE, Professor da PUC-RJ e da FGV-RJ \\ e-mail: a.alkmim@uol.com.br
}

Recebido: 03/01/2013

Aceito: 30/07/2013
RESUMO O presente artigo traz uma reflexão sobre o conceito e a prática da representação política, suas possibilidades e seus limites, especialmente trazendo à discussão o paradoxo lógico inerente à relação entre representados e representantes. Retoma o clássico livro de Hanna Pitkin (1967), no qual, partindo da etimologia e da história do conceito, refere-se aos tipos por ele engendrados para a atividade política, segundo a perspectiva liberal, alicerçada na democracia representativa. O contraponto crítico parte de Rousseau, com a centralidade do conceito de vontade política, e reúne posteriormente autores do campo da democracia direta em suas vertentes à esquerda, como os argumentos apresentados em um artigo de Paul Sartre e em considerações do pensador anarquista Lysander Spooner. Toma-se o breve exemplo histórico da Comuna de Paris, como um momento que propiciou uma reflexão de Marx sobre esta questão. Nas considerações finais, avalia-se a hipótese recorrente de que os princípios da representação seriam complementares. O paradoxo da representação sugere, a partir dos seus princípios lógicos e normativos que os procedimentos políticos podem até sobrepor-se, mas parecem ser sobretudo distintos e contrários. Representação e participação não seriam complementares, mas contrapostos.

PALAVRas ChaVe Representação política; Participação política; Democracia.

ABSTRACT This article presents a reflection on the concept and practice of political representation, its possibilities and its limits, especially bringing the discussion logical paradox inherent in the relationship between representatives and their constituencies. Reintroducing the classic book of Hanna Pitkin (1967), in which, from the etymology and history of the concept, refers to the types which he hath devised for political activity, according to the liberal perspective, founded on representative democracy. The critical counterpoint part of Rousseau, with the centrality of the concept of political will, and then gathers authors from the field of direct democracy in its tracks to the left, as the arguments presented in an article by Paul Sartre and considerations anarchist thinker Lysander Spooner. Takes up the brief historical example of the Paris Commune, as a moment that provided a reflection of Marx on this issue. In the concluding remarks, we evaluate the hypothesis applicant that the principles of representation would be complementary. The paradox of representation suggests, from its logical principles and normative political procedures may even overlap, but appear to be particularly distinctive and contrasting. Representation and participation would not be complementary but opposing.

KEYWORDS Political representation; Political participation; Democracy. 
"Representation means a presenting again, a presenting of something not present." Hanna Pitkin (1967: 71).

“O que não aparece não existe.” Lysander Spooner (1991: 97).

\section{Introdução}

O presente artigo traz uma discussão sobre o tema da representação delimitado na referência da teoria clássica, abordando o que denominamos de paradoxo do conceito de representação. Este paradoxo é derivado especialmente de dois textos da filósofa política Hanna Pitkin $(1967,2006)$. No primeiro estudo já se apresenta o paradoxo pela multiplicidade do conceito, a partir de sua gênese na teoria política, que segundo a autora emerge de Thomas Hobbes, no capítulo XVI de seu Leviatã. A partir daí derivam-se diversos sentidos para o termo, tipificados por Hanna Pitkin. Mas o paradoxo em si é formulado mais explicitamente no artigo de 1989, onde Hanna Pitkin (2006) revê suas idéias originais, invocando, o que não fez no primeiro estudo, a crítica ao conceito de representação inicialmente constituída por JeanJacques Rousseau em seu Contrato Social, apontando a impossibilidade lógica da representação política. A autora apresenta a partir daí uma outra linhagem de autores, passando por socialistas e anarquistas que também contraditam o princípio e a possibilidade da representação no plano político. Formam-se assim dois planos de análise distintos.

O paradoxo da representação política pode ser denotada como a impossibilidade de igualdade dos termos da $\mathrm{A}=\mathrm{B}$, pois na esfera do poder esta igualdade é logicamente impossível, porque um sujeito ou vontade pessoal não pode se expressar através de outro sujeito ou vontade. Desta forma, problemas relativos à participação política seriam reduzidos à gênese da própria representação.

O paradoxo da representação retomado neste estudo recolocou a discussão restritamente à linhagem clássica da matriz, na forma qualificada por Pitkin, e por conta desta delimitação não invoca um conjunto extenso e expressivo de importantes autores contemporâneos que abordam diretamente o tema, estabelecendo o limite de escopo da presente análise.

O estudo parte de um sugestivo artigo de Jean-Paul Sartre explicitando diversos aspectos relativos ao paradoxo da representação, remetendo a uma crítica de ordem marxista, que de alguma forma perpassa argumentos utilizados por outros críticos do conceito de representação. Embora sua argumentação sobre o processo eleitoral sirva como chave de abertura para a discussão, ainda lhe faltam argumentos que são apontados mais adiante.

A segunda parte do texto traz idéias centrais do estudo de Hanna Pitkin de 1967, apresentando a abordagem da teoria política do conceito de representação, em sua multiplicidade, seus limites, sendo estabelecidos modelos típicos ideais para alguns deles, a partir de Thomas Hobbes e outros autores da tradição clássica, embora não tenha sido incluída a referência ao filósofo John Locke. Esta tipologia serviu como base para uma nova tipologia proposta ao final deste artigo, alimentada também por outras teorias aqui discutidas.

O paradoxo lógico da representação emerge na seção seguinte, a partir do texto mais recente de Hanna Pitkin (2006), onde ela revisita o conceito e de forma diversa do seu ensaio anterior confronta a possibilidade da representação com a sua impossibilidade, em uma perspectiva original, claramente diferenciada e mesmo crítica ao conceito da representação. É em Rousseau, introduzido pela própria autora, que encontraremos a formalização do paradoxo.

$\mathrm{O}$ artigo segue, como uma complementação ao argumento favorável ao paradoxo da representação política, para além da mais recente posição crítica redefinida por Hanna Pitkin, incorporando nas duas partes seguintes novas discussões: uma trazida pelo pouco conhecido autor anarquista Lysander Spooner, que formula incongruências lógicas, desta vez direcionadas à experiência do pacto federativo americano. Outro aspecto incorporado ao estudo diz respeito à reflexão de Marx e Engels, calcada na curta experiência da Comuna de Paris, em 1871. Embora o tema da representação na sua forma parlamentar sempre tenha sido objeto de crítica destes autores, sem que apontassem, como Rousseau, o paradoxo aí inerente, foi a experiência francesa que de alguma forma os fez refletir sobre a articulação entre participação e representação no plano político, em um contexto alternativo de sociedade.

A parte final do estudo propõe um resumo e um modelo de tipificação de teorias de representação e seu modelo crítico calcado na participação, a partir da discussão estabelecida ao longo do ensaio, devendo, esta tipificação, ser entendida como um ponto de chegada, marcado por uma caracterização provisória e limitada, merecedora de uma melhor qualificação, à luz da incorporação de autores e teorias ausentes neste ensaio.

\section{Uma Posição Crítica à Representação: Jean-Paul Sartre}

Em 1973, o filósofo Jean-Paul Sartre publicou um artigo em que tecia uma ácida crítica ao sistema de 
representação contemporâneo, ao se defrontar com as eleições parlamentares na França, marcadas pela polarização ideológica decorrente das mobilizações do final da década anterior, assim como pela atuação cada vez mais voltada para a disputa parlamentar dos partidos Comunista e Socialista. De uma perspectiva marxista, o artigo, intitulado "Eleições, armadilha para otários", questiona os princípios da representação política. Seu argumento inicia-se na retomada do momento histórico de 1789.

Em 1789 foi estabelecido o voto censitário: votavam não os homens, mas as propriedades reais burguesas que sufragavam apenas a si mesmas. Esse sistema era profundamente injusto, uma vez que excluía a maior parte da população francesa do corpo eleitoral. Mas não era absurdo.

Os eleitores votavam isoladamente e em segredo: isso correspondia a separá-los uns dos outros e a admitir apenas vínculos de exterioridade entre os sufrágios. Mas os eleitores eram todos proprietários já isolados por suas propriedades: estas se fechavam sobre seus possuidores e repeliam coisas e homens com toda a sua impenetrabilidade material. As cédulas de votação, em quantidades discretas, apenas traduziam a separação dos votantes, esperando-se que, ao serem totalizados, os votos pusessem em evidência o interesse da maioria - isto é, o interesse de classe desta. (Sartre, 2004: 5).

Já nesta passagem, Sartre trata de duas questões centrais relativas à possibilidade de a vontade política ser efetivada através do sufrágio eleitoral: a individuação e o anonimato que se dão através do sufrágio universal e a restrição, para amplos segmentos da população, do exercício desse voto.

Os eleitores pertencem a agrupamentos os mais diversificados. Contudo, não é enquanto membros de um grupo, mas como cidadãos, que a urna os aguarda. A divisória instalada em uma sala de escola ou da Prefeitura é símbolo de todas as traições que o indivíduo pode cometer contra os grupos a que pertence. A cada um ela diz: "ninguém te vê, dependes apenas de ti; vais decidir no isolamento; depois, poderás esconder tua decisão, ou mentir sobre ela". Nada mais é necessário para transformar os eleitores que entram nessa sala em traidores potenciais uns aos olhos dos outros. E a desconfiança ainda aumenta a distância que os separa.

Se quisermos lutar contra a atomização, primeiro é necessário tentar compreendê-la. Os homens não nascem na separação: surgem no seio de uma família que os $f a z$ durante seus primeiros anos. $\mathrm{Na}$ sequiência de suas vidas, farão parte de diferentes comunidades sócio-profissionais e fundarão suas próprias famílias. Eles são atomizados quando grandes forças sociais - as condições de trabalho em regime capitalista, a propriedade privada, as instituições etc. - se aplicam sobre os grupos de que fazem parte para segmentá-los e reduzi-los às unidades de que se pretende sejam compostos. (Sartre, 2004: 6-7).

A condição de isolamento dos eleitores defrontados com a urna eleitoral reflete, portanto, uma condição de atomização, na qual esses eleitores encontram-se pulverizados, uma condição de alienação institucional. A atomização é uma condição presente na sociedade capitalista contemporânea que se manifesta no momento eleitoral, combinando-se com outro efeito da serialização, criando uma junção de seres atomizados, reunidos porém sem uma consciência coletiva mais geral, que, nesta condição específica, fazem a mediação com a realidade.

O ponto central da crítica de Sartre coloca-se logo a seguir, no ato da votação de homens atomizados, serializados e alienados da sua condição social:

Em uma palavra: quando voto, abdico do meu poder. Abro mão da possibilidade, presente em cada um, de, ao lado de todos os outros, constituir um grupo soberano. Renuncio a construir um grupo desprovido da necessidade de representantes. Afirmo que nós, os votantes, continuamos sendo outros que não nós mesmos, e que - a não ser por pessoas interpostas - nenhum de nós é capaz de abandonar a serialidade em benefício do grupo. (Sartre, 2004: 9).

$\mathrm{O}$ ato individual do voto secreto combina o efeito de atomização e serialização, alienante para cada eleitor, mas justificado pelo sistema eleitoral como um todo. No ato do voto abre-se mão do poder, da soberania da vontade política, pois submete-se essa vontade ao princípio da representação. A alienação daí decorrente é explicada pelo conjunto de características do sistema social como um todo, com a sua correlação de forças. Não se trata tão-somente de um princípio normativo, ainda que contraditório, que tem o seu molde no sistema de representação. O princípio da representação indireta é necessário dentro de uma estrutura de correlação de poder mais abrangente e que envolve a formação dos valores políticos, da própria opinião pública.

Tudo está bastante claro: se refletirmos, chegaremos à conclusão de que a democracia indireta é uma mistificação. Pretende-se que a Assembléia eleita seja a que melhor reflita a opinião pública. Mas só há opinião pública serial. A imbecilidade dos meios de comunicação de massa, as declarações do governo, a maneira parcial ou truncada pela qual os jornais refletem os acontecimentos, tudo 
isso vem encontrar-nos em nossa solidão serial e nos empanturrar de idéias pré-fabricadas, feitas daquilo que pensamos que os outros pensarão. (Sartre, 2004: 11).

A crítica de Sartre não deixa de fora os partidos de esquerda (Socialista e Comunista) que abraçam a ilusão parlamentar como uma perspectiva pragmática, maquiavélica, vislumbrando a possibilidade de chegar ao poder através das eleições. Na verdade, como ressalta Sartre, esse maquiavelismo, ao final, volta-se contra os Maquiavéis, pois o jogo político é bem delimitado nas suas fronteiras, que são as fronteiras do próprio sistema social como um todo. E os partidos políticos, ao entrarem no jogo da democracia representativa, nada mais fazem do que legitimar o próprio sistema social do qual deriva o sistema de representação.

Esse curto e contundente artigo de Sartre foi aqui retomado para trazermos à discussão um tema recorrente na teoria política e que trouxe um marco através do estudo publicado por Hanna Pitkin nos Estados Unidos em 1967, intitulado The concept of representation. Entre este livro, que se tornou referência no tema, e o artigo do filósofo francês existe certa convergência histórica, pois França e Estados Unidos assistiram, no final dos anos 1960, à emergência de movimentos sociais que sacudiram suas instituições políticas: no caso norte-americano, a luta pelos direitos civis, protagonizada pelos negros, postos à margem de um sistema político viabilizado pela democracia representativa, que deixava intocada a forte distinção racial. Do lado francês, uma conjuntura imediatamente posterior ao expressivo movimento estudantil que sacudiu o país, exigindo uma reforma educacional e trabalhista mas que, na verdade, tocava nos alicerces conservadores da nação, sob a égide gaullista.

A substância dos movimentos sociais que emergiram em diversas partes do mundo no final dos anos 1960 fez com que o liberalismo aprofundasse o seu conteúdo, levando ao questionamento também do modelo político adotado do Estado. No caso de Hanna Pitkin, a discussão do conceito de representação política possibilitou que se repensasse o sistema liberal à luz dos movimentos por direitos civis, políticos e sociais, permanecendo dentro dos limites do sistema de representação através do sufrágio universal. No caso de Sartre, há uma perspectiva de ruptura com esse sistema, que remete aos conceitos genuinamente marxistas de negação da democracia representativa, especialmente a parlamentar.

Pode-se remeter esta discussão àqueles que defendem a democracia representativa contra a crítica de sua inviabilidade, calcada nos pressupostos da democracia direta. Mas o ponto principal aqui ressaltado é o paradoxo da representação política a partir do ponto de vista lógico, evidenciando-se suas consequentes derivações no plano formal e substantivo. Por isto a crítica de Sartre é ainda incompleta. Incompleta porque enfatiza a crítica histórica e social, mas não formula uma crítica nos termos lógicos e formais relativos ao conceito de representação política, ao passo que a discussão proposta por Hanna Pitkin nos serve como uma mais precisa delimitação no âmbito teórico e conceitual. O paradoxo emerge de forma mais vigorosa no livro de Pitkin, e a autora faz uma tentativa de superação deste paradoxo ao atribuir o procedimento da representação ao plano institucional, apontando para um caminho pelo qual se pretende preservar a possibilidade da representação.

\section{Hanna Pitkin e o Conceito de Representação Política}

"Uma multidão de homens é transformada em uma pessoa quando é representada por um só homem ou uma só pessoa, de maneira que tal seja feito com o consentimento de cada um dos que constituem essa multidão. Porque é a unidade do representante, e não a unidade do representado, que faz com que a pessoa seja uma. E é o representante o portador da pessoa, e só de uma pessoa. Esta é a única maneira pela qual é possível entender a unidade de uma multidão." Thomas Hobbes (2004: 137).

O estudo de Hanna Pitkin sobre representação adota o procedimento epistemológico de traduzir o conceito em seus diferentes significados, buscando uma adequação histórica e teórica, enfatizando a dimensão política da representação.

Do ponto de vista político, aponta como marco a discussão trazida por Hobbes (2004: 135), especialmente no capítulo XVI de Leviatã, em que o autor inglês apresenta o ato de representar (representante, mandatário, lugar-tenente, vigário, advogado, deputado, procurador, ator) como um desdobramento da persona, que, segundo ele, define-se como:

[...] disfarce, ou a aparência exterior de um homem, imitada no palco. E por vezes mais particularmente aquela parte dela que disfarça o rosto, como representante da palavra ou da ação, tanto nos tribunais como nos teatros.

Hobbes define o termo segundo sua perspectiva contratualista, no contexto em que o Parlamento inglês confronta o poder absoluto de Carlos I, levando o país a uma guerra civil a partir de 1642, que teve como 
desfecho a prisão do Rei em 1647 e sua execução em 1649. Dois anos depois, Hobbes publicaria a sua obra mais importante, defendendo o absolutismo inglês, inovando em relação ao tradicional argumento absolutista que buscava a legitimação do poder real como originário do poder divino. Formulava então a idéia de que o poder político do Estado era derivado de um contrato de associação e de submissão, no qual a vontade política dos representados era transferida para o representante do Estado, de maneira irrevogável e irrestrita.

Segundo Hanna Pitkin (1967: 7), Hobbes introduz, no capítulo XVI de Leviatã, o conceito de representação, distinguindo as pessoas como naturais ou artificiais. Pessoas naturais verbalizam e agem por si sós, enquanto as artificiais verbalizam e agem por outrem. No último caso, forma-se a dualidade entre representados e representantes, básica para a formulação do contrato.

A representação, tomada como procedimento formal em Hobbes, é evidenciada na primeira categoria tratada por Pitkin, a representação por autorização. Apesar dos mais diferentes significados que a autora apresenta para esse tipo de representação, do ponto de vista estritamente político coloca-se a condição de transferência de poder, do autor (representado) para o ator (representante), que desempenha um papel irrevogável e de livre interpretação e ação.

Cada homem confere a seu representante comum sua própria autoridade em particular, e a cada um pertencem todas as ações praticadas pelo representante, caso lhe haja conferido autoridade sem limites. (Hobbes, 2004: 137).

A liberdade do autor é condição para a efetividade do contrato, necessário para a passagem do cruel estado de natureza para a artificialidade que conduz à vida social e à formação do Estado. Para Pitkin, no entanto, apesar de restrito, do ponto de vista das possibilidades, o conceito de representação em Hobbes já traz implícita uma responsabilização do representante, através não do direito, mas da obrigação de agir (Pitkin, 1967: 19), formulada por um pacto do qual, inicialmente, todos participam e segundo o qual a ação do representante é ilimitada (Pitkin, 1967: 20), cabendo aos representados a obrigação de obedecer-lhe.

Assim, Hobbes fornece teoricamente a justificativa da obrigação política (Pitkin, 1967: 29), após a autorização dada ao representante. Esta, para Pitkin, seria uma das duas possibilidades de interpretação da representação de uma perspectiva formalista, que, nos termos hobbesianos, funda-se na autorização de um conjunto maior $\mathrm{A}$, para que uma pessoa ou um grupo
B exerça o poder político em seu nome, sendo que B estava inserido em A no momento do pacto que elege o representante. A esse tipo de representação Pitkin denomina "acting for", e, segundo ela, também se desenvolve a idéia da necessidade de uma

[...] responsabilização a posteriori (originária do pensamento liberal), na qual a essência da representação é a accountability ou responsividade do representante. (Loureiro, 2009: 67).

Pitkin distingue outro tipo formal de representação que se afirma no campo da teoria e da prática política: a representação como sintonia ou semelhança entre o representante e o representado. A identidade entre representante e representados, embora não conceituada na forma mais sistemática pela qual aparece na formulação de Hobbes, encontra-se implícita em outro contratualista inglês, John Locke, em um período imediatamente posterior ao de Hobbes, posicionado ao lado da Revolução liberal de 1689.

De acordo com Locke, em seu Segundo Tratado do Governo Civil (2009), o contrato social não desnaturaliza o homem pela sua artificialidade, tratando-se, antes, de um procedimento de adequação da natureza humana que preserva a liberdade e a igualdade políticas. O liberalismo de Locke inscreve uma nova perspectiva de representação, no que se aproxima do tipo apresentado por Hanna Pitkin como "standing for", onde o representado A mantém uma ligação intrínseca com o representante $\mathrm{B}$, através da atividade legislativa.

Em Locke, o pacto social surge em decorrência do estado de natureza, quando os homens formam uma comunidade por associação e consentimento racional dos indivíduos, cuja finalidade é a formulação, a interpretação e aplicação das leis:

Quando qualquer número de homens, através do consentimento de cada indivíduo, forma uma comunidade, dão a essa comunidade uma característica de um corpo único, com o poder de agir como um corpo único, o que significa agir somente segundo a vontade e a determinação da maioria. Pois o que move uma comunidade é sempre o consentimento dos indivíduos que a compõem, e, como todo objeto que forma um único corpo deve mover-se em uma única direção, este deve se mover na direção em que o puxa a força maior, ou seja, o consentimento da maioria; do contrário, é impossível ele atuar ou subsistir como um corpo, como uma comunidade, como assim decidiu o consentimento individual de cada um; por isso cada um é obrigado a se submeter às decisões da maioria. E por isso, naquelas assembléias cujo poder é extraído de leis positivas, em que a lei positiva que os 
habilita a agir não fixa o número estabelecido, vemos que a escolha da maioria passa pela escolha do conjunto, e importa na decisão sem contestação, porque tem atrás de si o poder do conjunto, em virtude da lei da natureza e da razão. E assim cada homem, consentindo com os outros em instituir um corpo político submetido a um único governo, obriga-se, diante de todos os membros daquela sociedade, a se submeter à decisão da maioria e a concordar com ela; do contrário, se ele permanecesse livre e regido como antes pelo estado de natureza, esse pacto inicial, em que ele e os outros se incorporaram em uma sociedade, não significaria nada e não seria um pacto. (Locke, 2009: 60).

Em outra passagem, Locke desdobra seu argumento em favor do critério da maioria para a decisão dos assuntos da comunidade, exceto nos casos em que o pacto defina outro critério de decisão.

Ao considerar o poder legislativo o mais importante poder da comunidade, Locke (2009: 71) afirma que os formuladores do pacto lhe devem obediência, a não ser que esse poder ultrapasse os termos do próprio pacto, encontrando-se este poder em ruptura com os ditames do direito natural:

A primeira lei positiva fundamental de todas as comunidades políticas é o estabelecimento do poder legislativo; como a primeira lei natural fundamental, que deve reger até mesmo o próprio legislativo, é a preservação da sociedade e (na medida em que assim o autorize o poder público) de todas as pessoas que nela se encontram. $\mathrm{O}$ legislativo não é o único poder supremo da comunidade social, mas permanece sagrado e inalterável nas mãos em que a comunidade um dia o colocou; nenhum edito, seja de quem for sua autoria, a forma como tenha sido concebido ou o poder que o subsidie, tem a força e a obrigação de uma lei, a menos que tenha sido sancionado pelo poder legislativo que o público escolheu e nomeou. Pois sem isso faltaria a esta lei aquilo que é absolutamente indispensável para que ela seja uma lei, ou seja, o consentimento da sociedade, acima do qual ninguém tem o poder de fazer leis, exceto por meio do seu próprio consentimento e pela autoridade que dele emana. Por isso, toda a obediência que pode ser exigida de alguém, mesmo em virtude dos vínculos mais solenes, termina afinal nesse poder supremo e é dirigida pelas leis que ele adota; jamais um membro da sociedade, pelo efeito de um juramento que o ligaria a qualquer poder estrangeiro ou a qualquer poder subordinado na ordem interna, pode ser dispensado de sua obediência ao legislativo e agir por conta própria; da mesma forma, também não é obrigado a qualquer obediência contrária às leis adotadas, ou que ultrapasse seus termos; seria ridículo imaginar que um poder que não é o poder supremo na sociedade possa se impor a quem quer que seja.

Embora não discuta a representação nos termos de Locke (que é citado apenas uma vez em todo o livro), Hanna Pitkin faz referência direta a outros autores como John Adams, John Stuart Mill, Walther Bagehot, relacionando-os à compreensão da representação política como retrato, miniatura, espelho, mapa (Pitkin, 1967: 60-61), pintura (Pitkin, 1967: 67-69), amostra (Pitkin, 1967: 74):

Despite their various assumptions and implications, the metaphors of picture and map and mirror, of miniature and sample, and the concept of representativeness all seem to have this in common: they involve a representativeness very different from that defined by de formalistic theorists, primarily a "standing for" something or someone absent some correspondence of features. They constitute generally what we may call (following Griffiths) "descriptive representation" in which a person or thing stands for others "by being sufficiently like them". (Pitkin, 1967: 80).

A representação do tipo descritivo, mesmo não prescindindo do critério da maioria para a decisão coletiva, deverá buscar uma acurada proporcionalidade dos representados do ponto de vista da sua segmentação, dando uma importância para as minorias que se formam como segmento e opinião. Citando John Stuart Mill, Pitkin (1967: 64) assegura que, nesse caso, a representação não deve ser confundida com o critério da maioria para a tomada das decisões políticas, sendo este um instrumento de decisão, um instrumento de ação e não de representação.

Outra forma de tratar o conceito de representação, ainda sob o aspecto da representação como "standing for", é a representação simbólica, diferenciada da representação descritiva. Estes dois tipos de representação, segundo Pitkin (1967: 111), agregam significado ao conceito restrito da representação formalística.

De maneira geral, a representação simbólica assume diferentes formas, nas mais diversas atividades humanas. Uma cruz pode ser a representação do Cristianismo, um ponto vermelho um atributo em um mapa, assim como um rei ou diplomata pode simbolizar um país ou nação, ou mesmo um funcionário pode ser considerado representante de uma empresa, mesmo que seja apenas um trabalhador comum dessa empresa. Em geral, segundo Pitkin (1967: 100) a representação simbólica no plano político baseia-se em um componente afetivo, 
emocional, psicológico ou irracional, mais do que em um critério racional ou arbitrário, sendo que muitas vezes recorre-se a rituais para reafirmá-la (Pitkin, 1967: 103).

A representação simbólica denota uma inversão de sentido, na medida em que é o representante que gera e reforça as imagens e ações assumidos pelos representados, sendo a relação entre A (representado) e B (representante) enfatizada pelo seu contrário, chegando-se ao limite, como ressalta a autora, às experiências totalitárias e fascistas (Pitkin, 1967: 107).

Uma vez apresentada sua tipologia básica, Pitkin atualiza a discussão sobre o conceito de representação ao considerar a controvérsia sobre o mandato independente ou imperativo (tendo como referência Edmund Burke) e ainda a noção de interesse, tanto dos representados quanto dos representantes. Pitkin afirma ao final a sua própria concepção de representação, deslocando o eixo de atenção para os polos da relação entre representados e representantes, para a própria relação em si, pois os dois polos apresentam interesses e características diferenciados, tornando a discussão pertinente tanto aos meios quanto aos fins do procedimento de delegação, ou, na definição da autora, uma atividade substantiva, na qual estão envolvidos interesses e na qual as decisões não dependem meramente de competência, não sendo escolhas tão-somente arbitrárias (Pitkin, 1967: 212).

Dessa perspectiva, interessa avaliar a atividade da representação como uma atividade institucionalizada:

Perhaps when we conventionally speak of political representation, representative stand in the kind of one-to-one, person to person relationship to his constituency or to each constituent in which a private representative stands to his principal. Perhaps, when we call a governmental body or system "representative", we are saying something broader and more general about the way it operates as an institutionalized arrangement. And perhaps even the representing done by an individual legislator must be seen, in such a context, as embodied in a whole political system. (Pitkin, 1967: 221).

Pitkin (1967: 224) procura deslocar o ponto da questão para o sistema de representação em si, pressupondo-o racional, mesmo que os representados tenham as mais diferentes motivações, os mais diversos interesses ou comportamento irracional:

The readiness of citizen A to vote for a certain candidate, derived from a casual conversation with $\mathrm{B}$, who got it from overhearing $\mathrm{C}$ discuss an article in publication $\mathrm{D}$ - this readiness be able to muster a single reason for his vote, and may not care about the immediate issues. Perhaps it is to this kind of public opinion that representative must be responsive, and can be responsible.

Conforme exemplifica Pitkin (1967: 230), governos representativos, como os exercidos nos Estados Unidos, na Inglaterra e na Suíça, de formas diferentes asseguram eleições livres, direito de voto, e que os representantes tenham um poder efetivo e que a oposição exerça o seu papel.

[...] we show a government to be representative not by demonstrating that its subjects have control over its subjects but just the reverse, by demonstrating that its subjects have control over what it does. Every government's actions are attributed to its subjects formally, legally. But in a representative government this attribution has substantive content: the people really do act through their government, and are not merely passive recipients of its actions. A representative government must not merely be in control, not merely promote the public interest, but must also be responsive to the people. The notion is closely related to the view of representing as substantive activity. (Pitkin, 1967: 232).

Apesar dos pressupostos apontados para um entendimento da representação como um processo substantivo da relação entre representados e representantes, do processo institucionalizado, principalmente, através da escolha livre, através de eleições para os representantes - que, a despeito de sua autonomia, devem exercer seu papel com responsabilidade, sendo pelos eleitores controlados. Para Pitkin existirá sempre uma constante tensão entre o ideal da efetividade do sistema de representação e aquilo que é realmente alcançado. Ou seja a ênfase da proposta relativista e institucional defendida por Pitkin neste momento recai sobre a legitimidade dos procedimentos, do processo democrático, capaz de com suas características tornadas públicas e exercitadas, ser capaz de garantir o êxito e a estabilidade do sistema político.

\section{Paradoxo Lógico da Representação}

"As palavras e o mundo mudam juntos, mas não em simples correlação direta." Hanna Pitkin (2006: 15).

Em um artigo publicado originalmente em 1989, Hanna Pitkin retoma a discussão do seu livro produzido em 1967, mais de duas décadas antes desse ensaio mais recente. Em seu livro, Pitkin trata do conceito de representação em seus diferentes significados, ressaltando a sua centralidade no campo da teoria política e de sua materialização 
histórica. Partindo de Thomas Hobbes, fixa-se na tradição liberal, procurando ao final justificar a aplicação do conceito de representação como processo institucionalizado de forma sistêmica, possibilitando a representação através das eleições e estabelecendo os mecanismos de controle para o seu funcionamento.

No artigo de 1989, Pitkin desdobra a discussão etimológica, inspirada em Wittgenstein e também já exposta no apêndice de seu livro (capítulo intitulado "On ethmology"), detalhando um pouco mais o histórico sobre o significado do conceito, partindo inicialmente do sentido tomado de empréstimo ao latim, língua em que representare indica 'tornar presente ou manifesto', 'apresentar novamente', ou 'trazer à presença' (Pitkin, 2006: 3). O termo ganha força política no contexto da fórmula liberal inglesa, com a acepção hobbesiana que lhe empresta a noção de autorização. Como ressalta a autora, a discussão do conceito desenvolve-se pelos séculos XVIII e XIX, através de prolongadas lutas políticas e institucionais.

[...] o sufrágio, a divisão em distritos e a proporcionalidade, os partidos políticos e os interesses e políticas, a relação entre as funções legislativas e executivas e as instituições legislativas e executivas. Essas lutas políticas precipitaram um corpo considerável de literatura, sistematizada de tempos em tempos, enriquecida e redirecionada pela teoria política. (Pitkin, 2006: 16).

Ainda segundo Pitkin, a discussão desemboca em uma disputa entre diferentes concepções sobre o mandato dos representantes, no que se refere à sua independência, questão que se encontra no cerne do debate contemporâneo:

A "polêmica sobre o mandato e a independência" é um daqueles debates teóricos infindáveis que nunca parecem se resolver, não importa quantos pensadores tomem posição em um lado ou no outro. Esse debate pode ser sintetizado nessa escolha dicotômica: um representante deve fazer o que seus eleitores querem, ou o que ele acha melhor? A discussão nasce do paradoxo inerente ao próprio significado de representação: tornar presente de alguma forma o que, apesar disso, não está literalmente presente. Mas, na teoria política, o paradoxo é recoberto por várias preocupações substantivas: a relação entre os representantes na legislatura, o papel dos partidos políticos, na medida em que os interesses locais e parciais se encaixam no bem nacional, a forma pela qual a deliberação se relaciona com o voto e ambas se relacionam com o exercício do governo etc. (Pitkin, 2006: 16).

Encontramos aí uma evidenciação do paradoxo da representação, ainda que restrita aos termos ou polos nos quais se funda o processo. A ênfase deve ser colocada no termo A da relação (representados) ou no termo B (representantes). Além de evocar a posição de Burke, Pitkin também ressalta a importância da fórmula do sistema político norte-americano que tem na representação um processo de filtro qualificado dos representantes, dando a ela um caráter mais elitista e menos democrático, a despeito da complexa institucionalização experimentada no desenho federalista daquele país.

$\mathrm{O}$ que basicamente diferencia o artigo de Pitkin é a recorrência ao pensador ausente na formulação anteriormente exposta em seu livro, um feroz crítico da possibilidade da representação no plano político: Jean-Jacques Rousseau.

Assim, para todas as formas de liberalismo existe, no final, algo como um interesse público objetivo, que deve de alguma maneira incluir e abarcar o verdadeiro interesse próprio de longo alcance de cada um. Dessa forma, apesar das alegações em contrário dos utilitaristas, cada indivíduo não é o melhor juiz do seu próprio interesse. $\mathrm{Na}$ verdade, se o julgamento do interesse fosse verdadeiramente subjetivo e pessoal a cada indivíduo, uma representação significativa seria impossível.

Essa é a posição adotada por Jean-Jacques Rousseau. Rousseau não argumenta em termos de interesse, mas de vontade, e a vontade é verdadeiramente pessoal. Uma pessoa pode ter vontade no lugar de outras, mas não há garantia de que essa vontade de um coincidirá com as vontades dos outros. Assim, as pessoas são livres apenas quando se autogovernam; as pessoas são obrigadas de forma legítima apenas pelas leis que elas "ratificaram pessoalmente", pelas leis aprovadas por sua própria vontade, expressa em participação direta. (Pitkin, 2006: 26-27).

Ao final do texto, faz ainda uma curta digressão sobre a perspectiva da posição socialista, que de qualquer forma não lhe parece tão radical como a de Rousseau:

De modo geral, pensadores posteriores ignoraram a perspectiva de Rousseau, considerando-a bizarra e idiossincrática. Quase ninguém que apoiava a democracia duvidava que a representação era a sua forma moderna, seu equivalente indireto. Se o governo representativo tinha defeitos, esses defeitos eram atribuídos ao sistema eleitoral particular, ao sistema partidário ou à exclusão de algum grupo do sufrágio. Mesmo a maioria dos críticos socialistas da democracia liberal não questionou a representação em si, mas a sua autenticidade sob o capitalismo. (Pitkin, 2006: 27-28) 
É feita ainda uma referência aos anarquistas, a qual, embora seja um tanto desqualificada, traz uma outra abordagem que remete à tradição alternativa à abordagem liberal, cujo enfoque é a participação direta.

Apenas em décadas recentes alguns pensadores novamente começaram a questionar esses pressupostos, reanimaram aquelas poucas e débeis vozes - algumas socialistas, outras anarquistas, todas mais ou menos bizarras e desviantes - que continuavam a desafiar a própria idéia de representação, a desafiar não apenas sua superioridade em relação à democracia participativa direta, mas mesmo sua capacidade de substituir o velho ideal. Esses pensadores têm sugerido que a participação no poder público e a responsabilidade podem ter um valor intrínseco e não apenas instrumental, necessário, portanto, ao bem da vida e ao pleno desenvolvimento dos seres humanos. Eles têm sugerido que apenas um povo ativo e com envolvimento político é livre e que as instituições representativas, inicialmente projetadas para abrir o domínio público para o povo comum anteriormente excluído, têm, de fato, servido para desencorajar a cidadania ativa. (Pitkin, 2006: 27-28).

Chegamos aqui ao ponto central da formulação do paradoxo lógico do conceito de representação, na gênese da aplicação do conceito com Thomas Hobbes. Tal paradoxo pode ser assim formulado: a representação política é uma impossibilidade lógica. Em um sistema eleitoral representativo, os termos A (representados) e B (representantes) não podem jamais ser igualados, senão no momento exato da votação. A equação $\mathrm{A}=\mathrm{B}$ pode ser validada logicamente pela matemática ou pela teoria dos conjuntos, mas tão-somente do ponto de vista abstrato. A ação política exige a vontade expressa dos cidadãos, que antecede o seu consentimento, a sua autorização ou delegação. Como ressalta Rousseau (2005) no seu Contrato Social: a vontade é inalienável e não se representa.

No século seguinte ao da formulação de Hobbes (2004) e Locke (2009), Rousseau (2005) faz, em 1757, a crítica à possibilidade da representação, formulando as bases para a defesa de outro ramo da árvore genealógica da ação política baseada na participação (exercício direto da vontade política) em detrimento da representação.

Cada um dando-se a todos não se dá a ninguém e, não existindo um associado sobre o qual não se adquira o mesmo direito que se lhe cede sobre si mesmo, ganha-se o equivalente de tudo que se perde, e maior força para conservar o que se tem. Se se separar, pois, do pacto social aquilo que não pertence à sua essência, ver-se-á que ele se reduz aos seguintes termos: "cada um de nós põe em comum sua pessoa e todo o seu poder sob a direção suprema da vontade geral e recebemos, enquanto corpo, cada membro, como parte indivisível do todo. (Rousseau, 2005: 71).

A soberania, expressão da vontade geral é inalienável, indivisível, está sempre correta, e não pode ser representada:

\begin{abstract}
A soberania não pode ser representada pela mesma razão por que não pode ser alienada, consiste essencialmente na vontade geral e a vontade absolutamente não se representa. É ela mesma ou é outra, não há meio termo. Os deputados do povo não são, nem podem ser, seus representantes; não passam de comissários seus, nada podendo concluir definitivamente. É nula toda lei que o povo diretamente não ratificar; em absoluto, não é lei. O povo inglês pensa ser livre e muito se engana, pois só o é durante a eleição dos membros do Parlamento; uma vez estes eleitos, ele é escravo, não é nada. Durante os breves momentos de sua liberdade, o uso que dela faz mostra que merece perdê-la. (Rousseau, 2005: 187).
\end{abstract}

Trata-se, portanto, da negativa enfática da possibilidade do procedimento representativo, instaurando-se o paradoxo lógico.

A perspectiva de Rousseau funda outra tradição, encorpada pelos movimentos políticos do século XVIII e que terá, na França, sua Revolução de 1789 e seus desdobramentos no ziguezague político e institucional desse país que, em cem anos após a Revolução de 14 de julho, vivenciou praticamente todas as experiências de formas de governo descritas pelos analistas políticos e historiadores.

Nesse momento histórico de instabilidade política na França, destaca-se a experiência da Comuna de Paris de 1871, desenvolvida em um curtíssimo período e que fez convergir o apoio de comunistas, socialistas e anarquistas que enxergaram ali, evidentemente considerando suas peculiares perspectivas, a possibilidade de desenvolvimento de um sistema político calcado na participação direta. Antes, porém, de examinarmos esse momento da conjuntura francesa, vamos avaliar o argumento de um anarquista norte-americano que trouxe novos elementos sobre o paradoxo lógico da representação, no contexto da guerra civil, da escravidão e da afirmação do pacto federativo dos Estados Unidos, a partir de um texto publicado em 1870.

\section{Um Argumento sobre a Inviabilidade do Pacto de Representação}

"Quando um homem planta uma árvore para si e para sua posteridade, deve ser entendido que 
ele não quer obrigar seus filhos a comer frutas." Lysander Spooner (1981: 96).

Lysander Spooner foi um pensador, ativista político e empresário que tentou constituir uma empresa alternativa de Correios, a qual obteve êxito comercial mas acabou por sucumbir ao monopólio do Estado americano, em decorrência de diversas leis restritivas a esta atividade. Tendo vivido entre 1808 e 1887, assumiu uma posição vigorosamente contrária à escravidão, ao mesmo tempo em que via o perigo das prevalecentes forças federativas do Norte do país, que na sua perspectiva instituíram um formato desequilibrado de poder, dada a sua supremacia em relação ao Sul, ainda que escravista. Por outro lado, Spooner entendia que o pacto federativo não poderia ser válidado universalmente, por ser restrito aos que dele haviam participado diretamente, e não podia sustentar-se ao longo do tempo, por conta da perenidade da geração que o constituíra ${ }^{1}$.

A constituição não tem autoridade nem obrigação inerentes. Não tem nenhuma autoridade, a não ser pelo contato homem a homem. Nem mesmo pretende ser um contrato entre as pessoas. No máximo, pretende ser um contrato entre pessoas que viveram há 80 anos. E supõe-se que tenha sido um contrato apenas entre aquelas pessoas que haviam atingido a maioridade, tendo portanto a capacidade de fazer contratos razoáveis e compulsórios. Além disso, sabemos historicamente que poucas pessoas daquela época foram consultadas, entrevistadas ou puderam expressar seu consentimento formalmente, e, caso tenham existido, estão todas mortas. A maioria já morreu há 40, 50, 60 ou 70 anos. E a Constituição, por ser o seu contrato, morreu com eles. Não tinham poder natural nem o direito de torná-la obrigatória a seus filhos. [...]

Esse acordo, como um acordo, só pode comprometer as pessoas existentes. Em segundo lugar, não asseguraria nenhum direito, poder ou disposição para compelir sua "posteridade" a manter tal acordo forte. Apenas indicaria que um suposto bem-estar de sua posteridade foi um dos motivos que induziram as partes originais a entrarem em acordo. (Spooner, 1981: 95).

\footnotetext{
1 Para obtenção de informações biográficas sobre Lysander Spooner, consultar <http://www.libertarianism.org/people/lysander-spooner>. Sobre suas ideias e o movimento anarquista em geral, ver George Woodcock (1981). Para uma avaliação crítica do anarquismo e suas inúmeras vertentes (política, sindical, individualista), uma referência básica é o verbete Anarquismo no Dicionário de política de Norberto Bobbio (2010).
}

O argumento, portanto, é bem específico sobre limites lógicos da representação como procedimento formal autorizativo, apontado o limite da extensão do corpo dos representantes; além disso, a impropriedade de pretender que o pacto se perpetue. Mas ainda falta ao argumento a especificação lógica que vai ao cerne da possibilidade da representação, incluindo o mecanismo do sufrágio através do voto.

Um entendimento implícito entre A, B e C, que, por voto secreto, irão escolher D como seu agente para privar-me da minha propriedade, da minha liberdade ou da minha vida, não autoriza de maneira alguma que D o faça. (Spooner, 1981: 97).

E mais adiante:

Mesmo esses pretensos agentes não sabem quem são seus pretensos mandantes. Eles agem secretamente, porque o voto secreto é um ato secreto. É como se fossem reunir-se em um conclave secreto na escuridão. São pessoalmente tão desconhecidos para os agentes que selecionam como para os outros. O pretenso agente não sabe pelo voto de quem ele foi selecionado e, consequentemente, quem são seus verdadeiros mandantes. Por não saberem quem são seus mandantes, eles não têm direito de dizer que têm algum. (Spooner, 1981: 98).

Encontramos então em Spooner o detalhamento da negativa da representação, a partir de um ponto de vista lógico, ainda que sem o pressuposto normativo de Rousseau, que enxerga na vontade exercida diretamente pelos cidadãos o poder político efetivo e legítimo. $\mathrm{O}$ argumento ganha o contorno processual, negando a realização do pacto a partir da sua gênese, pela não abrangência de todos os atores políticos, pela sua não atualização, e - o mesmo argumento utilizado por Sartre - pela escuridão intrínseca ao ato do voto secreto. $\mathrm{O}$ que se decide no anonimato não vale para todas as pessoas nem para todos os tempos.

Estando a crítica quase completa, a esta altura podemos fazer um contraponto a ela. Em que medida efetivamente pode-se formular uma alternativa consistente ao problema da representação, segundo o paradigma da democracia direta? Ou, mesmo com a explicitação do paradoxo da representação em sua gênese, até que ponto se deve superá-lo tendo em vista que o procedimento, ainda que incoerente, fundamenta-se normativa e culturalmente, e de fato se assentou institucionalmente, como o modo predominante de se pensar e aplicar politicamente a fórmula da democracia? Os acontecimentos na França entre março e maio de 1870 trazem outros 
pontos de reflexão que nos permitirão retomar estas duas questões.

\section{A Crítica Marxista sobre a Representação}

"O período que temos diante de nós abrange a mais alta e heterogênea mistura de contradições clamorosas: revolucionários declaradamente constitucionalistas; uma Assembleia Nacional que quer ser onipotente e permanece sempre parlamentar." Karl Marx (1978: 346).

Os eventos de Paris em 1871 são abordados aqui pois, embora na sua efemeridade, além de aglutinar na reflexão e na prática política diferentes correntes do emergente movimento anarquista e socialista francês, permitem, através do pensamento de Marx formular, em um termo mais restrito a crítica ao conceito de representação política, pois por um lado tanto Marx como Engels na conjuntura francesa desde 1848 colocam-se como opositores ao sistema parlamentar de representação, que é visto como um campo de disputa das classes dominadoras da sociedade capitalista (o argumento é retomado, como visto, em Sartre). Mas o sufrágio universal e o poder legislativo diretamente ligado ao executivo e submetido a um controle social direto, é defendido dentro do breve contexto de formação das comunas.

A Comuna de Paris que dura menos de dois meses, mas é reverenciada por socialistas, comunistas e anarquistas como o primeiro momento histórico em que o moderno proletariado toma o poder - entendido aqui na sua dimensão completa, estendida às esferas política, econômica, social, religiosa, cultural, educacional. $\mathrm{O}$ movimento histórico chega a propor uma revolução no cotidiano. A Comuna surge no momento em que o império de Napoleão II começa a ruir, a partir da captura do Imperador na guerra empreendida entre França e Prússia. O Exército prussiano sitia Paris, mas não avança na ocupação da cidade, pois se põe diante de um grande segmento da população urbana que dispôs as armas à serviço da causa revolucionária socialista, comunista ou anarquista. Isto foi suficiente para que o novo regime se instalasse, trazendo à memória a Revolução de 1789, atualizada pelos levantes de 1848 .

A Comuna de Paris, proclamada em 18 de março de 1871 , foi formalizada em 26 de março e durou até 28 de maio. Nesse período foi capaz de produzir uma plataforma radical até mesmo para os dias atuais e começar a implementar algumas delas. Embora longa, a citação seguinte é ilustrativa e reflete detalhadamente a plataforma diferenciada do movimento.
O trabalho noturno foi abolido; oficinas que estavam fechadas foram reabertas para que cooperativas fossem instaladas; residências vazias foram desapropriadas e ocupadas; em cada residência oficial foi instalado um comitê para organizar a ocupação de moradias; todos os descontos em salário foram abolidos; a jornada de trabalho foi reduzida, e chegou-se a propor a jornada de oito horas; os sindicatos foram legalizados; instituiu-se a igualdade entre os sexos; projetou-se a autogestão das fábricas (mas não foi possível implantá-la); o monopólio da lei pelos advogados, o juramento judicial e os honorários foram abolidos; testamentos, adoções e a contratação de advogados se tornaram gratuitos; o casamento se tornou gratuito e simplificado; a pena de morte foi abolida; o cargo de juiz se tornou eletivo; o calendário revolucionário foi novamente adotado; o Estado e a Igreja foram separados; a Igreja deixou de ser subvencionada pelo Estado e os espólios sem herdeiros passaram a ser confiscados pelo Estado; a educação se tornou gratuita, secular e compulsória; escolas noturnas foram criadas e todas as escolas passaram a ser mistas; imagens sacras foram derretidas e sociedades de discussão foram adotadas nas igrejas; a igreja de Brea, erguida em memória de um dos homens envolvidos na repressão da Revolução de 1848, foi demolida. O confessionário de Luís XVI e a coluna Vendôme também; a bandeira vermelha foi adotada como símbolo da Unidade Federal da Humanidade; o internacionalismo foi posto em prática: o fato de ser estrangeiro tornou-se irrelevante. Os integrantes da Comuna incluíam belgas, italianos, poloneses, húngaros; instituiu-se um escritório central de imprensa; emitiu-se um apelo à Associação Internacional dos Trabalhadores; o serviço militar obrigatório e o exército regular foram abolidos; todas as finanças foram reorganizadas, incluive nos correios, na assistência pública e nos telégrafos; havia um plano de rotatividade de trabalhadores; considerou-se instituir uma Escola Nacional de Serviço Público, da qual a atual ENA francesa é uma cópia; os artistas passaram a gerir teatros e editoras; o salário dos professores foi duplicado. ${ }^{2}$

Disputavam a hegemonia da condução desse movimento blanquistas, anarquistas e comunistas, representados por lideranças como Bakhunin e Marx, que tiveram influência e participação nos acontecimentos, bem como produziram uma reflexão teórica sobre eles. Em um texto introdutório à Guerra Civil na França, de autoria de Marx, publicado

\footnotetext{
${ }^{2}$ O texto foi capturado na Wikipedia em 20 de agosto de 2011, com base no clássico livro de Lissagaray (1991).
} 
posteriormente à primeira edição da obra, Engels (1977: 161) afirma a importância histórica do movimento:

Por fim, a 28 de janeiro de 1871, a cidade de Paris, vencida pela fome, capitulou. Mas com honras até então desconhecidas na história das guerras. Os fortes se renderam, as fortificações foram desarmadas, as armas das tropas da linha e da Guarda Móvel forram entregues e seus homens considerados prisioneiros de guerra. Entretanto, Guarda Nacional conservou suas armas e seus canhões, limitando-se a selar um armistício com os vencedores. E esses não se atreveram a entrar em Paris sob o toque do triunfo. Ousaram apenas ocupar um pequeno recanto da cidade, numa parte em que só havia parques públicos e, ainda assim, só os que haviam cercado Paris por 131 dias foram contidos pelos operários armados da capital, que montavam guarda atentamente a fim de que nenhum 'prussiano' ultrapassasse os estreitos limites do recanto cedido aos conquistadores estrangeiros. Tal era o respeito que os operários de Paris infundiam a um exército diante do qual haviam rendido suas armas todas as tropas do Império. E os junkers prussianos, que pretendiam vingar-se no berço da revolução, eram obrigados a parar respeitosamente e fazer a saudação militar a essa mesma revolução armada.

A reflexão de Marx sobre esse evento histórico, do qual foi ator relevante, é um recorte histórico pertinente à discussão, pois é o limite da sua busca, em sua segunda fonte filosófica: a primeira, a superação de Hegel; a segunda, a sua inserção no cenário pós-revolucionário francês; a terceira, a centralidade material (no estágio crítico para o hegelianismo), expressa na dimensão econômica (Lenin, 1979), chegando ao ponto de elaborar $O$ Capital, cujo objetivo é desvendar as leis que regem o sistema capitalista.

A fase francesa da biografia de Marx o faz defrontar-se com uma conjuntura especialmente inovadora e desafiadora de uma interpretação crítica, pois nos anos em que acompanhou esse processo Marx $(2012,1978)$ produziu seus escritos à luz dos acontecimentos, como o Manifesto Comunista (1848), em coautoria com Engels, e o 18 Brumário de Luís Bonaparte (1852). Sua reflexão sobre representação parte do contraponto filosófico e crítico à teoria de Hegel, onde o conceito de representação é invertido ganhando sua materialidade pela determinação da existência social prevalecente à consciência individual. Uma oposição direta ao círculo idealista dos denominados jovens hegelianos apresentada em A Ideologia Alemã (Marx e Engels, 1998). Esta perspectiva alcança nos anos seguintes suas formulações históricas em relação à conjuntura francesa, no cenário pós rousseauniano. Não há, no entanto, um vínculo teórico mais firmemente estabelecido entre o conceito de representação no plano filosófico e sua aplicação empírica histórica, embora o fio lógico esteja subjacente.

Se no Manifesto Marx e Engels (2012) apontam para a centralidade do proletariado no sistema de produção capitalista - daí a necessidade de uma sociedade governada por esta classe, governo denominado ditadura do proletariado -, no 18 Brumário (Marx, 1978), além da tentativa de decifrar a conjuntura, através do jogo de poder das classes sociais que afinal elegeriam, através de sufrágio universal, Luís Napoleão Bonaparte o segundo imperador, após a Revolução de 1789. Marx não deixa de fazer duras críticas ao sistema de representação francês, especialmente o sistema parlamentar, estabelecendo a ligação dos partidos com seus vínculos sociais, de classe. Em certa passagem do seu texto Marx faz uma observação sobre o Parlamento naquela conjuntura, postura classificada como cretinismo parlamentar.

Em outra passagem Marx (1978) estabelece a diferença entre o vácuo de poder deixado pela representação parlamentar contra o poder ascendente de Luís Bonaparte, poder esse que acaba tendo como legitimação o próprio sufrágio universal, elegendo, no desfecho desse processo, Luís Bonaparte imperador, tal como ocorrera com seu tio Napoleão I.

Enquanto cada representante do povo representa apenas este ou aquele partido, esta ou aquela cidade, esta ou aquela cabeça de ponte, ou até mesmo a mera necessidade de eleger algum dos setecentos e cinqüenta candidatos, sem levar na devida consideração nem a causa nem o homem, ele é o eleito da nação e o ato de sua eleição é o trunfo que o povo soberano lança uma vez a cada quatro anos. A Assembléia Nacional exibe realmente, em seus representantes individuais, os múltiplos aspectos do espírito nacional, enquanto que no presidente esse espírito nacional encontra sua emancipação. Em comparação com a Assembléia, ele possui uma espécie de direito divino; é presidente pela graça do povo. (Marx, 1978: 340).

$\mathrm{Na}$ verdade, Marx torna-se crítico do sistema de representação parlamentar, embora não negue a importância do sufrágio universal, aqui servindo para legitimar um poder imperial. Mas tudo se submete ao cenário em que ocorre o conflito entre as classes sociais, e no 18 Brumário ele ressalta que Luís Bonaparte acaba recebendo o apoio de uma expressiva massa extraparlamentar da burguesia (Marx, 1978: 386). 
[...] a burguesia de fora do Parlamento não compreende como a burguesia de dentro do Parlamento pode perder tanto tempo com disputas tão mesquinhas e comprometer a tranqüilidade pública com rivalidades tão tolas com o presidente. (Marx, 1978: 372).

Esse jogo, na conjuntura francesa de 1848 a 1852 , termina com a eleição de Luís Napoleão imperador, e, após o exercício de seu mandato, interrompido por sua captura pelo Exército prussiano, tem nesse outro contexto a emergência da breve experiência da Comuna, que é exaltada por Marx (1977: 196):

Antítese direta do Império era a Comuna. O brado de "República social", com que a Revolução de Fevereiro foi anunciada pelo proletariado de Paris, não expressava mais do que o vago desejo de uma república que não acaba com a forma monárquica de dominação de classe, mas com a própria dominação de classe. A Comuna era a forma positiva dessa República.

A crítica aqui formulada recoloca a questão do sufrágio universal, entendido como uma forma renovável de dominação política:

Em lugar de decidir uma vez, a cada três ou seis anos, quais membros da classe dominante devem representar e esmagar o povo no Parlamento, o sufrágio universal deveria servir ao povo organizado em comunas. (Marx, 1977:198).

Marx confronta a experiência da Comuna ao preceito da democracia representativa parlamentar, vivenciada pelos variados governos desse período, apontando o seu caráter diferenciado, ao mesmo tempo em que vê outra conotação para o sufrágio universal:
A Comuna era composta de conselheiros municipais eleitos por sufrágio universal nos diversos distritos da cidade. Eram responsáveis e substituíveis a qualquer momento. A Comuna devia ser não um órgão parlamentar, mas uma corporação de trabalho, executiva e legislativa ao mesmo tempo. (Marx, 1977: 197).

O elogio da Comuna traz, no seio da disputa teórica entre anarquistas e comunistas, pontos de vista divergentes quanto ao caráter da formação do governo e do Estado. Marx parte da idéia de ditadura do proletariado, formulada com Engels no Manifesto de 1848 , enquanto os anarquistas propõem a dissolução do Estado. À luz dos eventos de 1870, Marx entende que a democracia direta, inclusive o sufrágio universal expandido, seria o contraponto da representação parlamentar do Estado burguês.

Desta forma verifica-se que a crítica de Marx, menos ao conceito e mais à prática da representação no seu formato parlamentar, contextualizado historicamente, permite a formulação de uma crítica ao conceito em si, embora não nos termos rousseaunianos ou nos termos do paradoxo formalmente enunciado. Para Marx e Engels a participação política direta, o que envolve também um controle social correspondente, admite a possibilidade do sufrágio universal para o preenchimento de cargos executivos, onde a deliberação legislativa coletiva que outorga este poder é soberano. De alguma forma portanto, embora crítico, o argumento marxista não elimina ao todo a existência da representação, ao contrário a valoriza em determinada circunstância, quando o sufrágio universal submete-se ao poder e vontade coletivos.

\section{Considerações Finais}

"No momento em que se dá representantes, o povo não é mais livre, não mais existe." Jean-Jacques Rousseau (2005: 189).

O paradoxo da representação, como uma crítica aos sistemas que se fortaleceram a partir do final do século XIX, foi formulado de diferentes maneiras, mantendo-se um argumento vigoroso, embora boa parte dos pensadores políticos contemporâneos adote uma linha de sobreposição e/ou combinação dos modelos existentes.

Podemos resumir em alguns pontos as linhas de argumentação expostas ao longo deste artigo, sobre o paradoxo da representação política:

- A formulação lógica da representação política não se sustenta, sendo impossível B representar A, pois a vontade não se representa;

- A identidade dos representados não coincide com a identidade dos representantes, do ponto de vista tanto da opinião como da segmentação social;

- A obscuridade do sufrágio universal secreto, que não pode ser considerado um pacto diretamente formado pelos cidadãos;

- Qualquer pacto político firmado não pode ter valor para as gerações seguintes;

- O processo político, na forma da representação parlamentar, atende interesses dentro da estrutura de classes da sociedade, mas não é aí o centro de gravidade do poder;

- Atomização e serialização do eleitorado como efeito do sufrágio universal, através do voto secreto, dificulta ou impede a formação de uma consciência coletiva, não alienada.

Estas restrições colocam o modelo crítico como antagônico aos demais modelos justificatórios da representação política. Inspirados pela classificação de Hanna Pitkin, chegamos a uma outra classificação, com cinco modelos ou tipos ideais, que toma como 
contraponto o modelo crítico e apresenta outras quatro formas, de acordo com as possibilidades representativas.

\section{Modelo 1: autorizativo}

A ênfase recai sobre o representante, ainda que seja instituído pelo ato de associação e vontade dos representados (conforme explicitado por Hobbes, seu principal defensor), restritos pelos limites da sua condição natural. A partir do momento em que se forma o governo, este atua como representante do Estado exercendo seu poder de forma absoluta. Outra vertente é encontrada em Burke, na sua defesa do mandato virtual, em que o representante se sobrepõe ao interesse daqueles que nele votaram defendendo os interesses da nação como um todo. Outro exemplo, ainda, são os federalistas que concebem um sistema federativo baseado na contraposição de poderes e no equilíbrio, e no qual a formação do governo e do legislativo obedece ao princípio da representação como filtro para controle das facções e recrutamento de uma elite política. Modelos autoritários baseados na representação simbólica, conforme tipifica Pitkin, também se aproximam deste modelo. As figuras 1 e 2 trazem os esquemas da análise proposta.

\section{Modelo 2: liberal}

A ênfase da representação encontra-se no representado. O contrato por consentimento torna o representante fiel aos representados em seus direitos a propriedade, liberdade e igualdade em sintonia com a sua condição natural. O Poder Legislativo é considerado supremo. A representação através do Parlamento e a formação do Poder Executivo devem estar em consonância com aqueles que firmaram o pacto formulando as leis, interpretando-as de acordo com a justiça e o bem comum e, finalmente, executando-as. $\mathrm{O}$ critério decisório se dá pela formação da vontade da maioria, expressa pelo poder supremo do Legislativo.

\section{Modelo 3: crítico}

Negativa da representação. Apresentação do paradoxo: B não pode representar A, distorção inevitável entre vontade e realização da vontade pela representação; falácia eleitoral, as eleições denotam uma correlação de forças na sociedade como um todo, uma sociedade dividida em classes; o pacto da representação não pode comprometer todos e não tem validade para as gerações precedentes; o voto secreto opera na escuridão; o sistema de representação através do voto atomiza e serializa. Na variante marxista a existência do sufrágio universal é subordinado expressamente à vontade coletiva.

\section{Modelo 4: identidade}

Modelo descritivo de representação, que encontra em John Stuart Mill um dos seus principais defensores. Identidade ou sintonia entre os elos na relação de representação. Visão da representação como retrato, miniatura, mapa, espelho, amostra da população, quanto aos seus atributos sociais, demográficos, segmentos de opinião. Defesa de representação das minorias. Exemplos contemporâneos e a apresentação dos regimes denominados consociacionais são encontrados em Arend Lijphart.

\section{Modelo 5: processual}

Mesmo considerando-se o paradoxo da representação, admitindo-se que o sistema é, em sua origem, normativo e apresenta limites, este modelo coloca a ênfase na representação como processo substantivo,

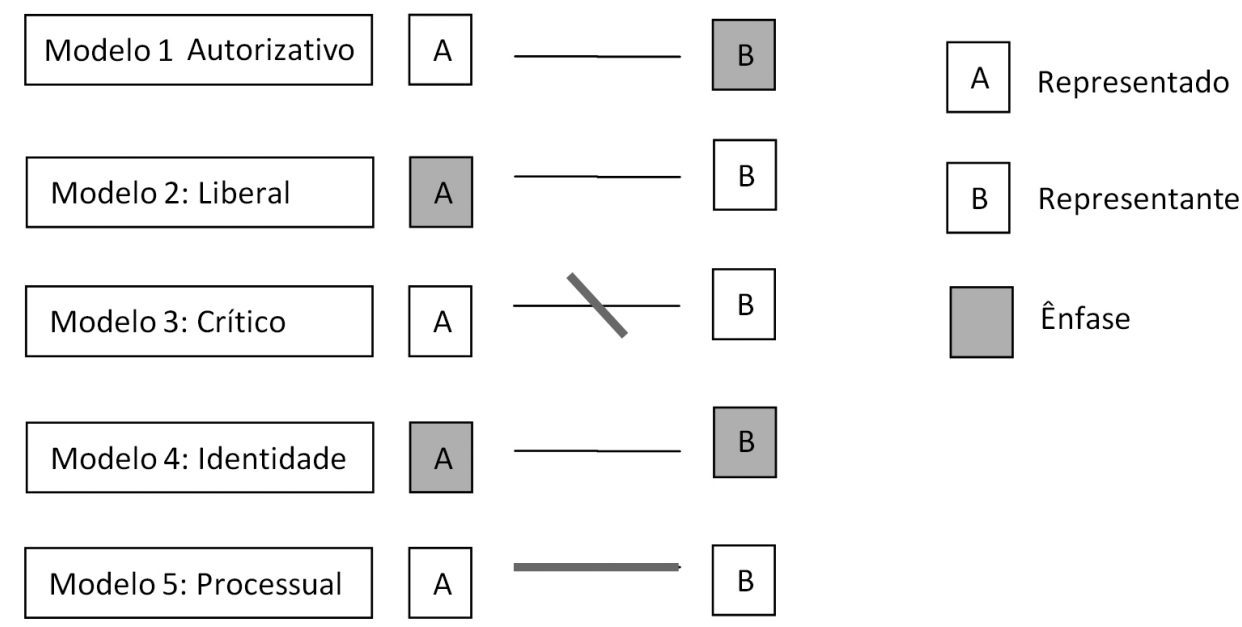

Figura 1. Possíveis modelos derivados do conceito de representação. 


\begin{tabular}{|c|c|c|c|c|c|}
\hline Século & $\begin{array}{l}\text { Modelo } 1 \\
\text { Autorizativo } \\
\text { Simbólico }\end{array}$ & $\begin{array}{c}\text { Modelo } 2 \\
\text { Liberal }\end{array}$ & $\begin{array}{c}\text { Modelo } 3 \\
\text { Crítico } \\
\text { Participativo } \\
\text { Mandato Imperativo }\end{array}$ & $\begin{array}{l}\text { Modelo } 4 \\
\text { Identidade } \\
\text { Descritivo }\end{array}$ & $\begin{array}{c}\text { Modelo } 5 \\
\text { Processual } \\
\text { institucionalização } \\
\text { Substantivo, } \\
\text { Responsabilização }\end{array}$ \\
\hline \multirow[t]{3}{*}{ XVII } & $\begin{array}{c}\text { Hobbes } \\
\text { Leviatã } \\
1652 \\
\end{array}$ & & & & \\
\hline & & $\begin{array}{c}\text { Locke } \\
\text { Segundo tratado } \\
\text { sobre o governo civil }\end{array}$ & & & \\
\hline & & 1690 & & & \\
\hline \multirow[t]{3}{*}{ XVIII } & & & $\begin{array}{c}\text { Rousseau } \\
\text { O contrato social } \\
1757 \\
\end{array}$ & & \\
\hline & $\begin{array}{c}\text { Burke } \\
\text { Carta aos } \\
\text { eleitores de } \\
\text { Bristol } \\
1777 \\
\end{array}$ & & & & \\
\hline & $\begin{array}{c}\text { Hamilton, } \\
\text { Madison e Jay } \\
\text { O Federalista } \\
1788 \\
\end{array}$ & & & & \\
\hline \multirow[t]{4}{*}{ XIX } & & & & $\begin{array}{c}\text { Jonh Stuart } \\
\text { Mill } \\
\text { Considerações } \\
\text { sobre o goveno } \\
\text { representativo } \\
1861 \\
\end{array}$ & \\
\hline & & & $\begin{array}{c}\text { Spooner } \\
\text { A Constituição } \\
\text { indefensável } \\
1870 \\
\end{array}$ & & \\
\hline & & & $\begin{array}{c}\text { Marx } \\
\text { Guerra civil na França }\end{array}$ & & \\
\hline & & & 1871 & & \\
\hline \multirow[t]{3}{*}{$x X$} & & & & & $\begin{array}{c}\text { Hanna Pitkin } \\
\text { O conceito de } \\
\text { representação } \\
1967 \\
\end{array}$ \\
\hline & & & $\begin{array}{c}\text { Sartre } \\
\text { Eleições, armadilha para } \\
\text { otários } \\
1973 \\
\end{array}$ & & \\
\hline & & & $\begin{array}{c}\text { Hanna Pitkin } \\
\text { Representação: palavras, } \\
\text { instituições e idéias } \\
1989\end{array}$ & & \\
\hline
\end{tabular}

Figura 2. Proposta de modelos de teorias sobre representação política, por autores significativos, segundo a ordem cronológica dos textos de referência.

sendo necessários a definição e o aprofundamento do papel dos representados e dos representantes, através da institucionalização, sendo igualmente importante o estabelecimento de mecanismos de responsabilização dos atores políticos em suas diferentes funções. A democracia como processo estaria consolidada enquanto cultura institucionalizada.
No plano prático, estabeleceram-se ultimamente inúmeras tentativas de justificar o estreitamento da relação entre representantes e representados dentro do sistema liberal, predominante nas democracias ocidentais. Entretanto, do ponto de vista prático esta tentativa não se sustenta, em função do paradoxo inerente à representação. 
Ao trazer esta discussão teórica para o campo político prático, considerando as instituições quanto aos seus fundamentos e funcionamento notamos a sua atualidade, pois os mais diversos desenhos institucionais não deixam de remeter à tensão entre participação e representação. Um exemplo, no caso do Brasil é a proliferação de instâncias denominadas Conselhos Municipais que se pretendem multitemáticas do ponto de vista da gestão e pretendem estabelecer um vínculo entre a gestão local e a sociedade civil. Apesar de sua proliferação, os Conselhos, alguns formalmente exigidos por lei, não atingiram o seu intento, não indo em sua maioria além de instrumentos burocratizados, sem poder efetivo e muitas vezes controlados pelo poder executivo municipal ${ }^{3}$.

Uma outra questão, igualmente contemporânea, diz respeito ao papel dos meios de comunicação como interface política e que se suprepõe à participação política. A crescente importância deste novo ator, embora multifacetado, constitui um forte golpe ao princípio da participação política. A mídia se apresenta e representa, assumindo funções de intermediação de interesses, pressão. A mídia (ou as mídias) se firma por meio de rituais e espetáculos dentro de uma sociedade massificada, constituindo um elemento a mais na relação entre representados e representantes, tornando-a ainda mais complexa, aprofundando o paradoxo estabelecido entre os elos da representação.

É necessário, portanto, ir mais fundo na reflexão sobre participação e representação política na atualidade, o que nos remete a diversos outros autores aqui ausentes, como Joseph Schumpeter, Antony Downs, Maurice Duverger, Giovani Sartori, Norberto Bobbio, Robert Dahl, Adam Przeworki, Bernard Manin, Arend Lijphart.

De qualquer forma ficamos aqui com a posição de que a sobreposição entre democracia representativa e participativa e parece ter levado ao predomínio da primeira sobre a segunda. Não existiria uma possibilidade de convivência harmônica dos dois métodos, pois a hipótese, a ser empiricamente testada, é que um método será predominante sobre o outro, não apenas do ponto de vista político mas também socialmente. $\mathrm{O}$ aprofundamento da democracia direta, no contexto das democracias liberais parece levar, no seu limite, não a uma acomodação e equilíbrio

\footnotetext{
A Pesquisa de Informações Básicas Municipais, levada a campo pelo IBGE, a partir de 1999 faz o acompanhamento sobre a existência e funcionamento dos Conselhos Municipais no Brasil, de onde se permite supor que apesar da grande proliferação destas instâncias no país (em 1999 eram 26,9 mil) os Conselhos não desempenharam até o momento um papel central nas administrações, seja quanto ao fundamento da participação política, seja quanto à autonomia e representatividade a eles teoricamente conferidos.
}

mesmo que dinâmico do sistema político, mas ao esgarçamento do paradoxo lógico da representação aqui referido.

\section{Referências}

Bobbio, Norberto. 2010. Dicionário de Política. 13. ed. Brasília: Editora UNB.

Hobbes, Thomas. 2004. Leviatã ou matéria, forma $e$ poder de um estado eclesiástico e civil. São Paulo: Abril Cultural. (Coleção Os Pensadores). [Original de 1651].

Lenin, Vladímir Ílitch. 1979. As três fontes e as três partes constitutivas do marxismo. São Paulo: Editora Global. [Original de 1913].

Lissagaray, Hippolyte Prosper-Olivier. 1991. História da Comuna de 1871. São Paulo: Ensaios. [Original de 1870].

Locke, Jonh. 2009. Segundo tratado sobre o governo civil. Rio de Janeiro: Editora Vozes. [Original de 1690].

Loureiro, Maria Rita. 2009. Interpretações contemporâneas da representação. Revista Brasileira de Ciência Política, 1: 63-93.

Marx, Karl e Engels, Frirdrich. 1998. A ideologia Alemã. 2. ed. São Paulo: Martins Fontes.

Marx, Karl e Engels, Frirdrich. 2012. Manifesto do Partido Comunista. São Paulo: Editora Expressão. [Original de 1848].

Marx, Karl. 1978. 18 Brumário de Luis Bonaparte. São Paulo: Abril Cultural. (Coleção Os Pensadores). [Original de 1852].

Marx, Karl. 1977. Luta de classes na França. In: INTRODUÇÃO de Engels, Friedrich. Karl Marx e Friedrich Engels, textos, volume 1. São Paulo: Editora Alfa-Õmega. [Original de 1871].

Orso, Paulino José. 2002. Parte I. In: P. J. Orso; F. Lerner e P. Barsoti, A Comuna de Paris de 1871: história e atualidade. São Paulo: Ícone Editora.

Pitkin, Hanna Fenichel. 1967. The concept of representation. Berkley: University of California Press.

Pitkin, Hanna Fenichel. 2006. Representação: palavras, instituições e idéias. Lua Nova, 67: 15-47. [Original de 1989].

Rousseau, Jean-Jacques. 2005. Do contrato social. São Paulo: Abril Cultural. (Coleção Os Pensadores). [Original de 1757].

Sartre, Jean-Paul. 2004. Eleições, armadilha para otários. Alceu, Revista de Comunicação, Cultura e Política, 5(9). [Original de 1973].

Spooner, Lysander. 1981. A Constituição indefensável. In: G. Woodcock, Os grandes escritos anarquistas. Porto Alegre: L \& PM, Editores Ltda. [Original de 1870].

Wikipedia. 2011. Comuna de Paris. Disponível em: <http://pt.wikipedia.org/wiki/Comuna_de_paris $>$. Acesso em: 20 ago. 2011.

Woodcock, George. 1981 Os grandes escritos anarquistas. Porto Alegre: L \& PM, Editores Ltda. [Original de 1870]. 